\title{
Introduction to the Symposium on Urban Economics
}

\author{
Jason Barr ${ }^{1}$
}

Published online: 12 November 2019

(c) EEA 2019

The year 2007 represents a milestone for the people of Planet Earth. It was the first time in human history that the majority of the world's population lived in cities (World Bank 2019). Projecting forward, by the end of the twenty-first century, that figure is likely to be around $80 \%$. The future is decidedly urban.

Ironically, across many parts of the world, urbanization is old news. The first cities arose between the eastern shores of the Mediterranean Sea and the Tigris and Euphrates Rivers about ten thousand years ago. The settlement of Jericho, with a population of around 2000, formed in the eighth millennium BC. At its height at around $2900 \mathrm{BC}$, the city of Uruk, in southern Mesopotamia, could boast some 50,000 residents (O'Sullivan 2006). Independent of that, cities, and the civilizations they begat, arose in China in the second millennium BC, and in the Americas around 1200 BC (Anderson 2011; Lees 2015).

Yet, even though cities and urban living are ancient phenomena, urbanization on such a massive scale is wholly a modern fact - a product of the Industrial Revolution and the wealth that it created. In the USA, only in 1920 did the census record that most Americans were living in cities (Boustan et al. 2013). The UK, which controlled a global empire for two centuries, only yielded to a majority of urbanized residents just before the turn of the twentieth century (Beeson and Troesken 2006). In China, where urbanization today is beyond mega- the combined population of the nine largest cities in the Pearl River Delta is over 57 million-the country, as a whole, has an urbanization rate of only about 60\% (World Bank 2019).

While the rise and fall of cities and civilizations has a long and fascinating history, it is fair to say that cities in the twenty-first century have a much different story to tell. Although history can tell us why cities exist and why they grow or die, it can tell us less about the causes and consequences of living in a world marked by constant technological change, rapid human and factor mobility, and significant government intervention in many aspects of our lives. For that matter, the methods we have today to study urban life are, relatively speaking, brand new and the result of both technological change itself (access to modern computing) and the centurieslong trail of scientific inquiry and debate.

Jason Barr

jmbarr@rutgers.edu

1 Department of Economics, Rutgers University-Newark, Newark, NJ 07102, USA 
Perhaps no other scholar today embodies the twenty-first century methods of studying the twenty-first century city more than Professor Edward Glaeser of Harvard University. Professor Glaeser has spent his entire career investigating the economics of cities. He has been a pioneer in trying to understand what draws us to cities (e.g., Ellison and Glaeser 1999; Ellison et al. 2010); how cities allocate scarce resources (e.g., Glaeser et al. 2005, 2008); and how they impact our individual and collective well-being (e.g., Glaeser et al. 1996, 2016). ${ }^{1}$ No other economist today has had such a strong influence on how we study and understand the economics of urban life. This symposium is to honor his Presidency of the Eastern Economic Association in 2018.

The papers published here emerged from eight fascinating sessions on urban economics held at the 2019 meeting of the Eastern Economic Association in New York City. From these, six are presented that study vital issues related to urban economics. One paper investigates 57 cities around the word. Another one looks at cities across China. The rest focus on the USA: three of which investigate several cities, and one that focuses on America's largest city, New York. All of them are empirically focused in that they use unique datasets to test their hypotheses. Four papers are interested in government policies and how they, directly or indirectly, impact, for good or bad, individual well-being. Three papers focus on those in the lowest income strata. And three papers are concerned with health outcomes.

The first paper in the symposium is "Chinese Hukou Policy and Rural-to-Urban Migrants' Health: Evidence from Matching Methods," by Marta Bengoa and Christopher Rick. This work explores an unintended impact of China's hukou policy, which is essentially an internal visa system. When a person is born, her "citizenship" is tied to her place of birth. Public benefits, such as healthcare and education, are normally administered at the location of the hukou registration. For ruralto-urban migrants, this can potentially be problematic since there are many benefits they cannot obtain in their new locations. However, a fraction of these migrants, those with high skills, for example, can obtain an urban hukou.

This means that within cities there is a two-tiered system for migrants-those with and those without the urban hukou. In order to investigate the impact of urban hukou status on health outcomes for rural-to-urban migrants, Bengoa and Rick apply the method of coarsened exact matching and propensity score models. Their findings suggest that migrants with an urban hukou are able to maintain lower levels of blood pressure and are less likely to develop hypertension or nutritional problems as compared to migrants who are unable to obtain the urban hukou.

The next paper, "Do Vouchers Protect Low-Income Households from Rising Rents?", by Ingrid Gould Ellen and Gerard Torrats-Espinosa also relates to the unintended consequences of government policies, but, in this case, investigates a possible positive spillover. Currently, in the USA, some 2.2 million low-income residents receive housing vouchers to subsidize their monthly rental payments. The direct intention of the program is to allow these households to gain access to higher-quality housing that they might not otherwise afford.

1 Note that these citations of Edward Glaeser's work are just a tiny sample of his vast research output. 
Yet, many neighborhoods in central cities are undergoing rapid gentrification and price spikes. Ellen and Torrats-Espinosa investigate whether the voucher program has the unintended benefit of protecting voucher holders from rising rents coming from rapid urban growth. They find that although rising rents in metropolitan areas are associated with a slight increase in rent-to-income ratios among voucher holders, poor renters in general see significantly larger increases in rent-to-income ratios. In other words, the voucher program helps shield low-income households against some of the rising rents that urban growth has produced. Looking at voucher holders who move, they find little evidence that rising rents push them to worse neighborhoods; in fact, they find that voucher holders in central cities, on average, end up in lowerpoverty neighborhoods as rents rise.

The third article is "Vision Zero: Speed Limit Reduction and Traffic Injury Prevention in New York City," by Kristin Mammen, Hyoung Suk Shim, and Bryan Weber. The authors investigate whether a newly enacted policy in New York City had the intended effect. In particular, in 2014, New York City implemented its "Vision Zero" program in order to reduce traffic fatalities and injuries. In bustling cities like New York, pedestrians, cyclists, and motorists all seem to be in a kind of war against each other in an effort to get to their destinations as fast as possible. The negative impacts of this scramble are injuries and deaths. Vision Zero has the lofty goal of eliminating these fatalities.

The question that Mammen, Shim, and Weber bring to the symposium is whether one particular aspect of the program - the reduction of the speed limit on unsigned streets from 30 miles per hour to 25 miles per hour-did, in fact, reduce injuries and fatalities. They construct a monthly panel dataset that includes the entire population of streets. Employing difference-in-difference estimation to study the laws' impact after implementation in 2014, they find a $38.7 \%$ decline in casualties and a $35.8 \%$ reduction in crashes on treated streets relative to the remaining population of streets.

The fourth paper in the symposium, "Shadow Economies around the World: Evidence from Metropolitan Areas," by Ceyhun Elgin looks at a hidden aspect of urban economies. Because economists tend to work with easily measured data, like gross domestic product (GDP) or unemployment rates, it is easy to overlook the fact that much economic activity happens under the radar, so to speak. Elgin's goal is to provide estimates for the size of these hidden or shadow economies in cities around the world. He focuses specifically on economic activities that, if recorded, would contribute to official GDP.

Elgin uses a calibrated two-sector dynamic general equilibrium model to construct annual estimates of shadow economy size (as a percentage of GDP) for 57 metropolitan areas from 31 countries throughout the world from 2001 to 2016. In addition to fully describing and characterizing the constructed dataset, he also provides some stylized facts regarding the trends of these estimates and some of their correlates. He then uses the model to evaluate the effects of two policy tools: changing the tax burden and tax enforcement.

While the above papers look directly or indirectly at urban policies, the next paper in the symposium turns to the very important question of business successes and failures. One of the key reasons that cities exist is that firms can gain positive spillovers or agglomeration benefits from clustering. Thus, understanding how clustering 
impacts economic growth (or not) remains a vital area of research. In this vein, the work by Matt Saboe and Simon Condliffe, "Explaining New Firm Survival: Is the Firm, Owner, or Agglomeration at Fault?", estimates the effects of several sources of agglomeration on new firm survival.

The authors utilize the longitudinal Kauffman Firm Survey of almost 5000 USA start-ups from 2004 to 2011. Using a discrete-time nonparametric survival regression framework, they find several interesting results. First is that, in general, firm and owner characteristics matter more for new firm survival than agglomeration effects. Secondly, however, is that not all start-ups are affected equally by the regional agglomeration factors. In particular, their results suggest that location does matter for particular groups of entrepreneurs such as high-tech start-ups and those firms not based out of their homes.

The final paper in the symposium, by Jason Barr and Jennifer Johnson, is "Skyscrapers and the Happiness of Cities." In the USA, skyscraper construction has had a long and controversial history. Detractors claim they have too many negative impacts, such as shadows and traffic congestion, while economic theory suggests they are an efficient allocation of scarce urban land. This paper has two aims. First is to test to see whether tall building construction across the USA is consistent with urban economic theory. And second is to test for the degree to which skyscrapers might impact the well-being, or happiness, of cities.

Looking at the number of tall buildings and an index of well-being across 186 metropolitan areas, the authors find strong support for the efficiency of tall buildings, but do not find a strong relationship between happiness and building height, on average. They find a positive relationship between skyscrapers (buildings $100 \mathrm{~m}$ or taller) and happiness, and a negative relationship between high rises (35-99 $\mathrm{m}$ ) and happiness. But across specifications, statistical significance varies. As well, the authors find no impact of tall buildings on measures of physical or mental health. Taken together, the results suggest that skyscrapers do not negatively impact city happiness or health levels.

In conclusion, the six papers presented here well-represent the state of empirical investigations into urban economics. They employ the latest methods and new datasets. Individually, and as a whole, they generate invaluable insights.

Acknowledgements I would like to first thank Diego Nocetti for his tireless assistance with putting together this symposium. I would also like to thank Cynthia Bansak and Allan Zebedee for their editorial support. I am grateful to the contributing authors and peer reviewers for their helpful comments, which contributed to improving the quality of each paper. I am also grateful for the many participants of the eight sessions on urban economics at the 2019 Annual Meeting of the Eastern Economic Association, from which these papers come. All of the participants helped to generate a lively exchange of ideas. I would like to thank Alexandre Olbrecht for his assistance in organizing the symposium sessions. Finally, I would like to thank Edward Glaeser for his support and encouragement of this special issue.

\section{References}

Anderson, M. (ed.). 2011. Early civilizations of the Americas. Chicago: Britannica Educational Publishing. 
Beeson, P.E. and W. Troesken. 2006. When bioterrorism was no big deal (No. w12636). National Bureau of Economic Research.

Boustan, L.P., D. Bunten and O. Hearey. 2013. Urbanization in the United States, 1800-2000 (No. w19041). National Bureau of Economic Research.

Ellison, G., and E.L. Glaeser. 1999. The geographic concentration of industry: does natural advantage explain agglomeration? American Economic Review 89 (2): 311-316.

Ellison, G., E.L. Glaeser, and W.R. Kerr. 2010. What causes industry agglomeration? Evidence from coagglomeration patterns. American Economic Review 100 (3): 1195-1213.

Glaeser, E.L., J.D. Gottlieb, and O. Ziv. 2016. Unhappy cities. Journal of Labor Economics 34 (S2): S129-S182.

Glaeser, E.L., J. Gyourko, and R.E. Saks. 2005. Why have housing prices gone up? American Economic Review 95 (2): 329-333.

Glaeser, Edward L., Joseph Gyourko, and Albert Saiz. 2008. Housing supply and housing bubbles. Journal of Urban Economics 64 (2): 198-217.

Glaeser, E.L., B. Sacerdote, and J.A. Scheinkman. 1996. Crime and social interactions. The Quarterly Journal of Economics 111 (2): 507-548.

Lees, A. 2015. The city: A world history. New York: Oxford University Press.

O'Sullivan, A. 2006. The first cities. In A companion to urban economics, ed. R.J. Arnott and D.P. McMillen. London: Wiley.

World Bank. 2019. Urban population (\% of total population), 1960-2018. https://data.worldbank.org/ indicator/SP.URB.TOTL.in.zs. Accessed 25 Oct 2019.

Publisher's Note Springer Nature remains neutral with regard to jurisdictional claims in published maps and institutional affiliations. 